\title{
The Impact of Jordanian Shopping Malls' Physical Surrounding on Consumer Buying Behavior: Field Study
}

\author{
Mohammad R. Odeh ${ }^{1} \&$ H. Abu-Rumman As'ad ${ }^{2}$ \\ ${ }^{1}$ Assistant Marketing Manager, Smartbuy, Amman, Jordan \\ ${ }^{2}$ Professor in the Department of Marketing, Applied Science private University, Amman, Jordan \\ Correspondence: Mohammad R. Odeh, Assistant Marketing Manager, Smartbuy, Amman, Jordan. Tel: \\ 962-79-681-5582. E-mail: Moe_odeh@hotmail.com
}

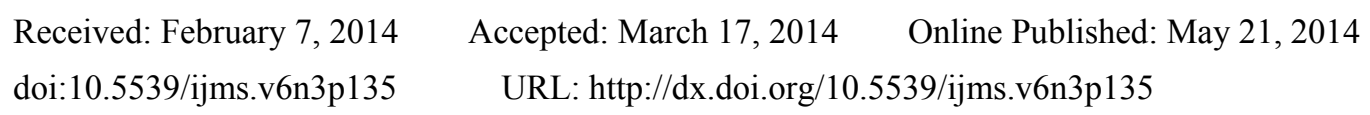

\begin{abstract}
Purpose-The purpose of this research is to investigate the physical surrounding and its elements such as ambient conditions, design factors, and social factors in Jordanian shopping malls and also its affect on consumer buying behavior to attract them to spend more money, spend more time, unplanned purchase , and also satisfactions. And the research found that there is a strong relationship between physical surrounding and its elements with consumer buying behavior.
\end{abstract}

Design/Methodology/Approach-convenience random sampling was employed to recruit 200 mal shoppers representing the desired range of demographic characteristics (e.g., age, level of education, gender, nationality, marital status, shopping time).

Findings - this paper showed that paying more attention to the physical surrounding will help in increasing consumer buying behavior by spending more time, money, and satisfaction.

Keywords: physical surrounding, ambient conditions, design factors, social factors, consumer buying behavior

\section{Introduction}

Physical surrounding is one of the marketing mix strategies. It has a great interest in service sector both the internal and external. Physical surroundings are the most used because they are the tangible aspect that consumers can realize. Physical surrounding is one of the important elements that affect in consumer behavior. Some people called it servicescapes and also environmental dimensions as Bitner, 1992. In many researches it consists of three factors: ambient condition as (color, music, scent, temperature, lighting, and air quality), design factors as (furnishings, style of décor, equipment, and also layout), and social factors as (personal, noise, signs, symbols, and artifacts) as demonstrated in (Bitner, 1992; Venkatraman \& Nelson, 2008; Chen \& Hsieh, 2011). Physical surrounding means the whole things that related to the environment and atmosphere surrounding the store such as sound, lighting, scent, and others. These factors strongly affect the consumers and their behaviors. For example, when you go to the mall and want to buy a T-shirt, the first thing you will look at is how the store looks like? Style of décor, colors, and many other things. A pleasant store atmosphere can prolong the time consumers spend in the store, increasing the likelihood that the consumer will find something he or she needs, as well as, increasing impulse buying (Chen \& Hsieh, 2011). Atmospherics have received a lot of attention from researchers, and music has received a large portion of that attention. Many in the field and some in the lab have identified relationships between affective qualities of music and specific behaviors of consumers (Gaygen, 2013). Physical surroundings help to shape appropriate feelings and reactions in customers and employees. Music can have powerful effects on perceptions and behaviors and also scent is another important ambient dimension. In addition to music and scent, researchers have found that colors have a strong impact on people's feelings. (Lovelock \& Wirtz, 2011). Now a day's Shopping centers had various kinds of store and most of countries grasp similar sales advertisings yearly. Throughout the sales advertising, retail shops frequently changes in physical surrounding with various kinds of music, décor and sales discount ranging from 25 to 75 per cent. This friendly environment transform would motivate and influence consumers purchasing behavior. It is frequent to monitor that shopping malls lean to put up remarkable physical surrounding as extrinsic value to draw customers to the mall and stores (Rizwan et al., 2013). It has been demonstrated by research over the years that sounds and music 
influence the shopping experience in retail atmospherics and can affect the consumers in tangible ways. Music in the retail space can be honed to reflect the brand, enhance the customer experience and reinforce consumer aspirations, promoting higher sales and is come to occupy an important place in the store atmospherics. (Kulkarni, 2012). And also perfume or scents play a vital role in affecting the behavior of consumer. For example, when it comes to buy a certain product in store that has a good smell would motive you to buy the product. The way the physical setting is created in organizations has barely been tapped as tangible organizational resource (Becker, 1981).

\section{Literature Review}

\subsection{Physical Surrounding and Consumer Buying Behavior}

Many researchers take the subject of physical surrounding in considering for improving buying and sales. As being showed in Sayed et al. (2003) of the title the effect of physical surroundings on Egyptian consumers' emotion states and buying intentions. The researchers found that each of the factors of the physical surroundings, with the exception of interior design, affects the amount of shopper pleasure, arousal, and dominance experienced. The population was shoppers (males and females) above age 16 who visit shopping malls in Alexandria and Cairo. Actual sample size was 308 after eliminating some invalid questionnaires. Of the total sample of 308, approximately $40 \%$ were from Alexandria and $60 \%$ from Cairo. The proportion of males was near $50 \%$ in both locations. Subjects were mainly (86\%) between the ages of 20 and 39 years, reflecting those who have purchasing power and frequently visit malls. The sample also was dominated by working men and women. Furthermore, the moderating responses of pleasure and arousal affect willingness to buy. This research provides useful insights for further research in the area of situational influences and its role in shaping consumer behavior. Factorial design could be conducted to measure the effect of some of those physical surrounding factors together rather than in isolation. For example, background music and lights or crowdedness can be presented in combination. Most of the researches indicated that physical surrounding or sometimes called it the environment positively affect the intentions inside buyers and motive them to buy or affect in negative way to leave out the place. The influence of mall shopping environment and motives on shoppers' response: a conceptual model and empirical evidence by Akroush, ElSamen and Jaradat (2011). This study aims to examine the influence of malls' shopping environmental cues, hedonic and utilitarian shopping motives on shoppers' response (satisfaction) through examining the mediating role of cognition (service quality) in shopping malls in Jordan. The sample was collected from 600 malls shoppers of which 390 were subjected for the analysis using structural equation modeling. The findings indicate that malls' environmental cues, hedonic and utilitarian shopping motives positively influence shoppers' experiential outcomes. Experiential outcomes positively influence cognitive outcomes and the later positively affect shoppers' response. The cognitive outcomes fully mediate the effect of shoppers' experiential outcomes on their satisfaction. Malls operators and investors have empirical findings regarding malls shoppers' buying behavior and drivers of their satisfaction to make sound strategic business decisions in developing countries, e.g., Jordan, the empirical testing and validation of the emotion-cognition-response model in Jordan' shopping malls. Using odors in malls is one of the successful ways to attract people to come and buy. And odors are one of the factors of physical surrounding. Parsons (2008) in his paper of use of Scent in a Naturally Odorless Store, he introduced the concept of associated scents for retail stores that are normally odorless and provide an understanding of how associated scent can be used by these non-scented retailers to influence shopper behavior and the appeal of the store. Previous studies have suggested that simply having a pleasant scent present can enhance liking for the store and encourage positive sales behavior, however, this study shows that for a store that is normally odorless the scent needs to have a perceived association with the store-type to gain positive responses. Presence of a pleasant but non-associated scent can actually lead to negative affective or behavioral responses. An important research implication is that the association of a non-product-specific scent with a particular (normally odorless) store might mean that encountering that scent elsewhere may trigger in the person thoughts of the store, which further research could show to be a motivator for visiting the store. Another implication is the need to identify best performing associated scents, and whether a retailer through a marketing campaign can create an artificial association, thus gaining a unique, sustainable competitive advantage. This study shows managers of normally odorless stores that they can gain a competitive advantage in their category through the identification and use of scent customers would associate with the store-type. One of the most important elements of servicescape is layout, and it is important how layout affect on consumer buying behavior. And the study by Liu et al. (2007) were trying to examine the effects of different store layout on signal-detection statistics, which take into account both intended purchases (hits) and unintended purchases (false alarms), and provide independent measures of the degree to which a shopper meets their shopping goal (sensitivity) and their strictness or impulsivity in making purchases 
response bias Fifty-seven subjects (13 female, 44 male) from Purdue University participated in the study for course credit. The nature of the procedures was explained fully. The finding showed that the hedonic shoppers that enjoy browsing in a store have an increased tendency to make unplanned purchases. Thus, our study demonstrates that the actual habits of these shoppers correspond with their self-assessed motivations, reflecting either a lax or strict criterion in purchase decisions. Moreover, we find that hedonic shoppers are less accurate overall in properly locating targeted items, due to the reported differences in shopping approaches between hedonic and utilitarian shoppers.

Another factor that should be in considers is Lighting. A research that matches this was by Quartier et al. (2008). The paper titled Retail design: lighting as an atmospheric tool, creating experiences which influence consumers' mood and behavior in commercial spaces. This paper addresses one aspect of atmosphere: lighting and its influence on consumers' mood and buying behavior. The concentration lies on the influence of lighting on the physiology of the human being operating on mood and consumer behavior through the perceptual system, beyond the conscious level. So, the association between the in-store lighting and consumer behavior will be examined. In depth interviews with twelve selected experts in Belgium and the Netherlands, all with a different background, were conducted. The following selection was made: four lighting developers of four different lighting manufacturers (two Belgian, a Dutch and a German company). The results show that there is a need for scientific development for lighting in food retailing. Even more, lighting is acknowledged to have an incremental added value to the retail environment, store branding and maybe even costumer binding.

Music also is one of ambient condition that plays a vital role affecting the consumer buying behavior. The primary goal of this research by Mandila and Gerogiannis (2012) is to examine the attitudes and the preferences of customers in retail stores. The main objectives of the research conducted were to: Test customer buying behavior under the influence of music, investigate the effects of music on time perception, customer satisfaction, investigate the effects caused on purchasing behavior and overall satisfaction by high-low volume of music as it is perceived by the customers, Measure the customers' overall satisfaction according to different types of music being played.And conduct a behavioral mapping of how customers act and react on hearing certain types of music and how it influences their purchases. The sample comprised 200 subjects that is a total of 100 subjects for each condition over the 8-day testing period ( 25 subjects a day). In the study of Stephanie Wilson, results indicated that different types of music had different effects on perceived atmosphere and the amount spent by the respondents. In the present study, the reasons of satisfaction were measured, showing that the different styles of music are not particularly related to the customers' overall satisfaction. It can be hypothesized:

Ho.1: There is no significant impact of the overall dimensions of shopping mall physical surrounding on consumer buying behavior.

Ho.1.1: There is no significant impact of ambient conditions on consumer buying behavior.

Ho.1.2: There is no significant impact of design factors on consumer buying behavior.

Ho.1.3: There is no significant impact of social factors on consumer buying behavior.

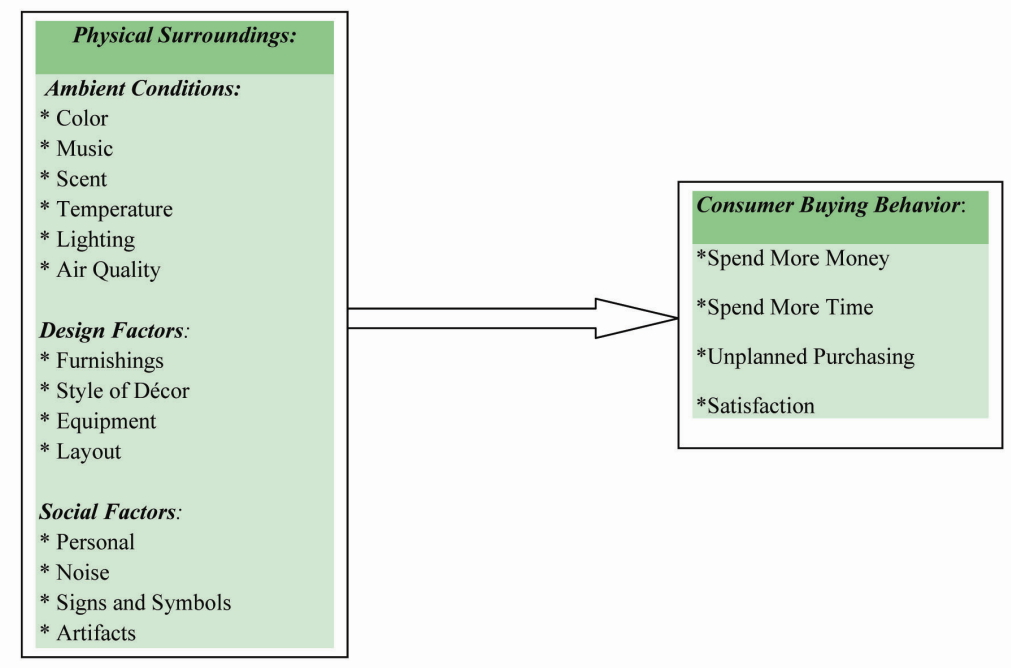

Figure 1. Research model 


\section{Research Objectives}

1) To figure out the impact of the content of the physical surrounding on consumer buying behavior in shopping malls;

2) Show the importance of physical surrounding as ambient conditions, design factor, and social factor for shopping malls;

3) Provide a theoretical framework to show the importance of their applications and their role in consumer buying behavior.

\section{Research Methodology}

\subsection{Population and Sample}

The population of the study is represented by the consumers who are available at Jordanian shopping malls; that this study deals with a sample of those consumers represented in Amman's shopping mall (Mecca mall, City Mall, Taj Mall).The study is focuses on the consumer who purchases their goods and services from mall shopping center, the unit sample is represented by the consumers who are available in the malls; that is because they are more capable in diagnosing the study variables, the sample that is used in this study called convenience random sampling. A total 200 of respondents were in the sample both males and females.

\subsection{Data Collection}

The research questionnaire was designed on the formats of previous empirical literature. The questionnaire design was through handing the customers who come to the malls the questionnaire. The research questionnaire was used as primary data collection method. The questionnaire was measure on 5-point likert- scale ranging from 5 (strongly agree) to 1 (strongly disagree).

\section{Results and Discussion}

Ho.1: There is no significant impact of the overall dimensions of shopping mall physical surrounding on consumer buying behavior.

Simple regression was performed and the results in table 1 showed that the strength of the relation between the overall dimensions of the physical surrounding and consumer buying behavior in Jordanian shopping malls was $(\mathrm{R}=71.6 \%)$, and the coefficient of determination $\left(R^{2}\right)$ showed that the explained difference percentage in the consumer behavior because of the impact of physical surrounding of Jordanian shopping malls is not less than $\left(R^{2=} .512\right)$, which is an acceptable percentage, meaning that (51.2\%) of the total differences in consumer buying behavior for the Jordanian is determined through the physical surrounding, and the remaining percentage is equal to $(48.8 \%)$ representing contribution percentage of the excluded variables that were not included in the study model as it shown in table 1 . The value of computed $(\mathrm{F}=208.112)$ in addition to significant level of $(0.000)$. This indicates that the curve of regression is good in explaining the relation between physical surrounding and consumer buying behavior.

Table 1. The impact of overall physical surrounding on consumer buying behavior

\begin{tabular}{llccl}
\hline Independent Variable & $\boldsymbol{\beta}$ & $\mathbf{T}$ & Sig \\
\hline Physical Surrounding & .716 & 14.426 & $.000^{*}$ \\
\hline
\end{tabular}

Note. $\mathrm{R}=.716 ; R^{2=} .512 ; \mathrm{F}=208.112 ;$ *significant level of $\mathrm{P} \leq 0.05$.

The results of the simple regression analysis showed that there is positive impact of the overall physical surrounding on the consumer buying behavior, $(\beta=.716)$ at level of significant $(0.000)$. Accordingly the researcher rejects the null hypothesis and accepts the alternative hypothesis.

\section{Ho.1.1: There is no significant impact of ambient conditions on consumer buying behavior.}

To test this hypotheses the researcher performs stepwise regression, the results show that the coefficient of determination $\left(R^{2}\right)$; which represents the percentage of the explained differences in the consumer buying behavior due to the physical surrounding dimensions is not less than $\left(R^{2}=.438\right)$ which is an acceptable result indicating that (43.8\%) from the total differences in the consumer buying behavior, the remaining which equals (56.2\%) represents the percentage of the excluded variables which were excluded from the study model as showed in table 2 below. 
In addition, the strength of the relation between the dimensions of physical surrounding and consumer buying behavior is $(\mathrm{R}=.662)$ as it shown in table 2 , the value of the computed $(\mathrm{F}=38.065)$ and significant level $(0.000)$ and that indicates that the regression curve is good in explaining the relation between the physical surrounding and consumer buying behavior.

Table 2. The impact of ambient condition on consumer buying behavior

\begin{tabular}{llll}
\hline $\begin{array}{l}\text { Independent } \\
\text { Variable }\end{array}$ & $\beta$ & $\mathrm{T}$ & $\mathrm{Sig}$ \\
\hline Air Quality & .258 & 3.652 & $.000^{*}$ \\
Lighting & .368 & 6.128 & $.000^{*}$ \\
Music & .148 & 2.566 & $.011^{*}$ \\
Scent & .134 & 2.080 & $.039^{*}$ \\
Color & .086 & 1.412 & .160 \\
Temperature & .105 & 1.411 & .160 \\
\hline
\end{tabular}

Note. $\mathrm{R}=.662 ; \mathrm{R}^{2}=.438 ; \mathrm{F}=38.065 ;$ *significant level of $\mathrm{P} \leq 0.05$.

After reviewing the analysis in table 2 results between the dimensions of the physical surrounding and consumer buying behavior; it is important to figure out whether the dimensions of physical surrounding affect in consumer buying behavior for the Jordanian shopping malls; so the percentage importance of the physical surrounding dimensions in the regression curve model indicates and with following the partial regression coefficient (Beta) for each dimension, table 2 shows that, the most important affecting dimensions are lighting and air quality $(\beta=.368 ; \beta=.258)$ in sequence.

\section{Ho.1.2: There is no significant impact of designs factors on consumer buying behavior.}

To test this hypotheses the researcher performs stepwise regression, the results show that the coefficient of determination $\left(R^{2}\right)$; which represents the percentage of the explained differences in the consumer buying behavior due to the physical surrounding dimensions is not less than $\left(R^{2}=.364\right)$ which is an acceptable result indicating that $(36.4 \%)$ from the total differences in the consumer buying behavior, the remaining which equals $(63.6 \%)$ represents the percentage of the excluded variables which were excluded from the study model as showed in table 3 below.

In addition, the strength of the relation between the dimensions of physical surrounding and consumer buying behavior is $(\mathrm{R}=.603)$ as it shown in table 3 , the value of the computed $(\mathrm{F}=37.401)$ and significant level $(0.000)$ and that indicates that the regression curve is good in explaining the relation between the physical surrounding and consumer buying behavior.

Table 3. The impact of design factors on consumer buying behavior

\begin{tabular}{llll}
\hline $\begin{array}{l}\text { Independent } \\
\text { Variable }\end{array}$ & $\beta$ & $\mathrm{T}$ & Sig \\
\hline Layout & .458 & 7.782 & $.000^{*}$ \\
Furnishing & .432 & 6.745 & $.000^{*}$ \\
Décor & -.186 & -2.842 & $.005^{*}$ \\
Equipment & .130 & 1.729 & .085 \\
\hline
\end{tabular}

Note. $\mathrm{R}=.603 ; \mathrm{R}^{2}=.364 ; \mathrm{F}=37.401 ;$ *significant level of $\mathrm{P} \leq 0.05$.

After reviewing the analysis in table 3 results between the dimensions of the physical surrounding and consumer buying behavior; it is important to figure out whether the dimensions of physical surrounding affect in consumer buying behavior for the Jordanian shopping malls; so the percentage importance of the physical surrounding dimensions in the regression curve model indicates and with following the partial regression coefficient (Beta) for each dimension, table 3 shows that, the most important affecting dimensions are layout and furnishing $(\beta=.458 ; \beta=.432)$ in sequence. 


\section{Ho.1.3: There is no significant impact of Social factors on consumer buying behavior.}

To test this hypotheses the researcher performs stepwise regression, the results show that the coefficient of determination $\left(R^{2}\right)$; which represents the percentage of the explained differences in the consumer buying behavior due to the physical surrounding dimensions is not less than $\left(R^{2}=.379\right)$ which is an acceptable result indicating that $(37.9 \%)$ from the total differences in the consumer buying behavior, the remaining which equals $(62.1 \%)$ represents the percentage of the excluded variables which were excluded from the study model as showed in table 4 below.

In addition, the strength of the relation between the dimensions of physical surrounding and consumer buying behavior is $(\mathrm{R}=.616)$ as it shown in table 4 , the value of the computed $(\mathrm{F}=39.956)$ and significant level $(0.000)$ and that indicates that the regression curve is good in explaining the relation between the physical surrounding and consumer buying behavior.

Table 4. The impact of social factors on consumer buying behavior

\begin{tabular}{llll} 
Independent & $\beta$ & $\mathrm{T}$ & Sig \\
\cline { 2 - 4 } Variable & & & $.000^{*}$ \\
Personal & .413 & 6.492 & $.001^{*}$ \\
Noise & .196 & 3.302 & $.003^{*}$ \\
Signs\& Symbols & .192 & 2.974 & .262 \\
\hline Artifacts & .076 & 1.125 & \\
\hline
\end{tabular}

Note. $\mathrm{R}=.616 ; \mathrm{R}^{2}=.379 ; \mathrm{F}=39.956 ;{ }^{*}$ Significant level of $\mathrm{P} \leq 0.05$.

After reviewing the analysis in table 4 results between the dimensions of the physical surrounding and consumer buying behavior; it is important to figure out whether the dimensions of physical surrounding affect in consumer buying behavior for the Jordanian shopping malls; so the percentage importance of the physical surrounding dimensions in the regression curve model indicates and with following the partial regression coefficient (Beta) for each dimension, table 4 shows that, the most important affecting dimension is Personal $(\beta=.413)$.

\section{Implications}

this study contributed to find out more about physical surrounding and its elements, because many researchers try to get a few variables but this study almost cover the whole thing based to physical surrounding and by this will help researcher to keep going through this term and also this will help retailers to increase their sales and money through know what customers prefer and what don't and this will create some innovation

\section{Conclusion}

This study potentially contributes to knowledge by examining the impact of physical surrounding on consumer buying behavior within Jordanian malls. This study could be useful for academics, retailers.... Academically, this work aims to focus academic attention on a much neglected domain such as what customer need to see, making them pay attention and motive them to buy. Many malls don't paying attention to physical surrounding and how this subject will attract people. There is currently a lack of appropriate study on this subject by academia in Middle East. Although this research has provided great points for physical surrounding, it is been subject to some limitations. One of these limitations was considered to be a new concept. Also there were no practical applications of this tool in Jordan and the Arab region possibly leading to some inconsistencies in the data collection process. Future research should take more variables to study with more details, and also should take more time to complete it and also sample should be more to get accuracy and reliability. Future research should be also expanded through other Arab countries.

\section{References}

Akroush, M., Elsamen, A., \& Jaradat, N. (2011). The Influence of Mall Shopping Environment and Motives on Shoppers' Response: A Conceptual Model and Empirical Evidence. International Journal of Services and Operations Management, 10(2), 168-198. http://dx.doi.org/10.1504/IJSOM.2011.042516

Becker, F. (1981). Workspace. New York: Praeger Publishers.

Bitner, M. (1992). Servicescapes: The Impact of Physical Surroundings on Customers and Employees. Journal of Marketing, 56(2), 57-71. http://dx.doi.org/10.2307/1252042 
Chen, H., \& Hsieh, T. (2011). The Effect of Atmosphere on Customer Perceptions and Customer Behavior Responses in Chain Store Supermarkets. African Journal of Business Management, 5(24), 10054-10066.

El Sayed, I., Farrag, D., \& Belk, R. (2003). The Effects of Physical Surroundings on Egyptian Consumers'Emotional States and Buying Intentions. Journal of International Consumer Marketing, 16(1), 5-28. http://dx.doi.org/10.1300/J046v16n01_02

Gaygen, D. (2013). Effects of Ambient Music Exposure on Simulated Buy Decisions. International Journal of Business and Social Science, 4(4), 184-194.

Kulkarni, V. (2012). A Study of Impact of Music on Customer Buying Behavior in Retail. International Journal of Management, 3(3), 152-159.

Liu, S., Melara, R., \& Arangarasan, R. (2007). The Effects of Store Layout on Consumer Buying Behavioral Parameters with Visual Technology. Journal of Shopping Center Research, 14(2), 63-72.

Lovelock, C., \& Wirtz, J. (2011). Services Marketing People, Technology, Strategy. New Jersey: Pearson Education.

Mandila, M., \& Gerogiannis, V. (2012). The Effects of Music on Customer Behaviour and Satisfaction in the Region of Larissa-The Cases of Two Coffee Bars. International Conference on Contemporary Marketing Issues. Thessaloniki.

Parsons, A. (2008). Use of Scent in a Naturally Odourless Store. International Journal of Retail \& Distribution Management, 37(5), 440-452. http://dx.doi.org/10.1108/09590550910954928

Quartier, K., Christiaans, H., \& Cleempoel, K. (2008). Retail design: lighting as an atmospheric tool, creating experiences which influence consumers' mood and behaviour in commercial spaces. Koenraad. Retrieved from http://shura.shu.ac.uk/496/

Rizwan, M., Javed, M., Khan, M., Aslam, M., Anwar, K., Noor, S., \& Kanwal, W. (2013). The Impact of Promotional Tools on Consumer Buying Behavior: A Study from Pakistan. Asian Journal of Empirical Research, 3(2), 118-134.

\section{Copyrights}

Copyright for this article is retained by the author(s), with first publication rights granted to the journal.

This is an open-access article distributed under the terms and conditions of the Creative Commons Attribution license (http://creativecommons.org/licenses/by/3.0/). 